\title{
Adverse effects of growth hormone replacement therapy in children
}

\author{
Efeitos adversos da reposição de hormônio \\ do crescimento em crianças
}

Flavio Moutinho Souza', Paulo Ferrez Collett-Solberg ${ }^{2}$

\begin{abstract}
SUMMARY
Human growth hormone (hGH) replacement therapy has been widely available for clinical purposes for more than fifty years. Starting in 1958, hGH was obtained from cadaveric pituitaries, but in 1985 the association between hGH therapy and Creutzfeldt-Jakob disease was reported. In the same year, the use of recombinant hGH (rhGH) was approved. Side effects of rhGH replacement therapy in children and adolescents include rash and pain at injection site, transient fever, prepubertal gynecomastia, arthralgia, edema, benign intracranial hypertension, insulin resistance, progression of scoliosis, and slipped capital femoral epiphysis. Since GH stimulates cell multiplication, development of neoplasms is a concern. We will review the side effects reported in all rhGH indications. Arq Bras Endocrinol Metab. 2011;55(8):559-65
\end{abstract}

\section{Keywords}

Growth hormone; side effects; gynecomastia; intracranial hypertension; scoliosis; pediatrics; short stature

\section{SUMÁRIO}

A terapia de reposição de hormônio de crescimento (hGH) tem sido amplamente disponível para uso clínico por mais de 50 anos. Inicialmente, em 1958, hGH era obtido de hipófises de cadáveres, mas em 1985 foi relatada a associação entre terapia com hGH e doença de Creutzfeldt-Jakob. No mesmo ano o uso de hGH recombinante (rhGH) foi aprovado. Os efeitos adversos que crianças e adolescentes em terapia de reposição de rhGH podem apresentar incluem erupção cutânea e dor no local da aplicação, febre transitória, ginecomastia pré-puberal, artralgia, edema, hipertensão intracraniana benigna, resistência insulínica, progressão de escoliose e epifisiólise da cabeça do fêmur. Como o GH estimula a multiplicação celular, o desenvolvimento de neoplasias é uma preocupação. Neste artigo, revisaremos os possíveis efeitos adversos do rhGH em cada uma de suas indicações clínicas. Arq Bras Endocrinol Metab. 2011;55(8):559-65

Descritores

Hormônio do crescimento; efeitos adversos; ginecomastia; hipertensão intracraniana; escoliose; pediatria; baixa estatura
1 Unidade Docente Assistencial de Endocrinologia, Hospital Universitário Pedro Ernesto, Universidade do Estado do Rio de Janeiro (UERJ), Rio de Janeiro, RJ, Brazil

${ }^{2}$ Laboratório de Pesquisas Clínicas e Experimentais em Biologia Vascular (BioVasc), Centro Biomédico, UERJ, Rio de Janeiro, RJ, Brazil
Correspondence to:

Paulo Ferrez Collett-Solberg

Laboratório de Pesquisas Clínicas

e Experimentais em Biologia Vascular, Centro Biomédico, UERJ, Pavilhão

Reitor Haroldo Lisboa

da Cunha (térreo)

Rua São Francisco Xavier, 524

20550-013 - Rio de Janeiro, RJ, Brazil

paulosolberg@yahoo.com

Received on 9/Oct/2011 Accepted on $17 / 0 c t / 2011$

\section{INTRODUCTION}

$\mathrm{H}$ uman growth hormone (hGH) has been used in GH deficient (GHD) children, adolescents and adults since 1958. The year of 1985 witnessed a switch from cadaveric pituitaries to recombinant hGH $(\mathrm{rhGH})$ obtained from DNA-recombinant techniques, after the reports of Creutzfeldt-Jakob disease in hGH recipients (1). There has never been a case report of CreutzfeldtJakob with the use of rhGH.
The first rhGH was approved in 1985. Since then, prescription has been approved not only for GHD but also to a series of non-GH deficient patients, such as chronic renal failure, Turner syndrome, children born small-for-gestational age without height catch-up, PraderWilli syndrome, idiopathic short stature, SHOX gene haploinsufficiency and Noonan syndrome (2).

In this report, we will review the side effects of the different therapeutic indications of $\mathrm{rhGH}$. 


\section{Growth hormone deficiency}

\section{Glucose metabolism}

GH physiologically antagonizes insulin effects in glucose and lipid metabolism by stimulating glycogenolysis and lipolysis, and inhibiting glycogenesis and lipogenesis. GHD is expected to increase insulin sensitivity, which can be clinically observed in GHD neonates with severe and persistent hypoglycemia at birth (3). Thus, treatment with rhGH is assumed to induce insulin resistance. This GH effect is observable, as type 2 diabetes mellitus (T2DM) is a classical feature in the context of excess GH in acromegaly (4). Nonetheless, there might be some increase in fasting and postprandial glucose and in plasma insulin during rhGH therapy, and the elevation may not be enough to overcome the threshold of glucose intolerance or T2DM in children who are not otherwise predisposed $(5,6)$. The incidence and age at diagnosis of type 1 diabetes mellitus during rhGH treatment is similar to the general population (7).

\section{Gynecomastia}

Prepubertal gynecomastia is a rare and self-limited adverse effect of children in use of rhGH $(8,9)$. It is characterized by the appearance of a breast bud in a prepubertal male, equivalent to the Tanner-stage 2 in normal female pubertal development. Reviewing "adverse drug experience" reports to United States Food and Drugs Administration (FDA) and data from pharmaceutical companies, Malozowski and Stadel reported 22 cases of prepubertal gynecomastia between ages of 2 and 12. The time from the initiation of therapy to the diagnosis of gynecomastia was found to be broad, varying between 0.5 month to 8 years. Since there was no data available on the number of children that have been exposed to $\mathrm{rhGH}$ in the populations from where the reports came, the incidence could not be estimated (9). Resolution occurred in two children after discontinuation of rhGH, and in five children still in use of the medication. Data was missing from the other cases (9). In general, there is no need for alteration in rhGH dosage, or discontinuation of medication, since gynecomastia is usually self-limited and will resolve with time.

\section{Slipped capital femoral epiphysis}

Slipped capital femoral epiphysis (SCFE) is defined as a posterior and inferior displacement of the proximal femoral epiphysis on the femoral neck (10). It occurs more frequently in periods of rapid height gain. Children with GHD are more prone to the development of SCFE, and rhGH replacement therapy may increase that risk by sevenfold. In a recent Kabi International Growth Study (KIGS) report, 52 from 57,968 children in rhGH therapy presented SCFE, in a total incidence of 73.4 per 100,000 patients year $(11)$, while in the general population prevalence is 10.8 cases per 100,000 (12). Clinical suspicion should be considered in children complaining of unilateral or bilateral pain in the hips or knees. Treatment is always surgical, and involves in-situ screw fixation (12).

The measurement of the diaphyseal-epiphyseal angle (Southwick's angle), using anteroposterior pelvic radiography, at the beginning of therapy and annually thereafter, may be useful to assess individual risk. During normal growth spurt, Southwick's angle is expected to decrease with time, whereas it is significantly increased during rhGH treatment, leaving the patients at risk of epiphysiolysis (13).

\section{Benign intracranial hypertension}

Benign intracranial hypertension (BIH) or pseudotumor cerebri is the result of the physiological antidiuretic effect of hGH and is more evident in patients that cannot support a decrease in glomerular filtration rate. Normal children exhibit a mild transitory elevation in plasma renin activity and aldosterone, and rarely develop BIH unless other predisposing factors are present. Pseudotumor cerebri can be clinically suspected in children complaining of headaches, nausea, vomiting and presenting papilledema at fundoscopic examination. Cautioun should be taken so as not to misdiagnose papilledema in children with septo-optic dysplasia and optic disc hypoplasia, which are congenital defects and strengthen the diagnosis of GHD (14).

In patients with signs compatible with pseudotumor cerebri, clinical or imaging examinations should be performed. If the diagnosis of pseudotumor cerebri is confirmed, rhGH should be discontinued temporarily, and reinitiated later on, at lower doses.

\section{Malignancies}

As both GH and insulin-like growth fator-1 (IGF-1) have mitogenic and anti-apoptotic properties, there has always been a concern that rhGH might induce tumorigenesis. There are three issues involved in the relationship between $\mathrm{GH}$ and neoplastic induction: 1) 
recurrence of a previously treated tumor; 2 ) induction of a second neoplasm; 3 ) appearance of a de novo malignancy.

GHD is one of the most common endocrine after-effects in the treatment of several malignancies. Surgical approach to intracranial tumors may affect the hypothalamus-pituitary axis, and therefore induce GHD, as well as cranial and whole-body radiotherapy for brain and neck tumors and leukemia.

The report of twelve cases of hematologic malignancy in a Japanese cohort on rhGH therapy raised concern on the safety of the medication (15). Eight of the patients had idiopathic GHD, and therefore leukemia would be a de novo malignancy; three had GHD secondary to cancer treatment; and one had Fanconi's anemia, which is a condition intrinsically associated with high incidence of leukemia (16). Despite the high risk of leukemia observed in the Japanese study, these results could not be replicated by other cohorts. The current position on the subject states that rates of new leukemia in non-Japanese patients without any known risk factors, and on rhGH replacement therapy are no greater than the expected ones for the general population (17).

The Childhood Cancer Survival Study (CCSS) follows up 13,539 survivors of childhood cancer. In the cohort of 361 patients treated with $\mathrm{rhGH}$, the relative risk of developing a second neoplasm, mostly meningioma, was 3.21 (95\% confidence interval, 1.88-5.46) (18). Additional 32 months of follow-up of the same cohort brought the relative risk down to 2.15 (95\% CI, 1.33-3.47), still significant (19). Attenuation of relative risk over time may indicate that rhGH therapy anticipates the occurrence of a second neoplasm, which cancer survivors are already at risk. This speculation might be confirmed if further updates of the cohort with longer follow-up show progressive decrease in the relative risk. Cranial irradiation itself increases the risk of a second neoplasm, especially meningioma (20). Indeed, Mackenzie and cols. did not find significant difference in the incidence of a second neoplasm between rhGH-treated and untreated patients submitted to cranial radiotherapy (21).

Hence, in relation to the three issues, current data suggests that the use of rhGH does not increase the risk of development of malignancy, although it is still unclear whether the incidence of meningiomas might be increased in patients with GHD secondary to cranial irradiation. Yet, since in the normal population higher serum levels of IGF-I have been epidemiologically associated with increased risk of malignancy (22), monitoring is imperative, so that IGF-1 serum levels do not exceed the normal range for sex and age.

\section{Long-term mortality}

In December 2010 the French drug agency (AFSSAPS) and the European Medicines Agency (EMA) were informed of preliminary data of the SAGhE (Santé Adulte GH Enfant) study. SAGhE is a multinational European epidemiological study designed with the purpose to establish the long-term mortality rate in young adults who, during infancy and adolescence, initiated rhGH treatment between January 1985 and April 1997. France was the first country to start the study and was later followed by other European countries. Of the 6,928 French patients considered at low risk for mortality (isolated idiopathic growth hormone deficiency, short stature in children born small for gestational age, and idiopathic short stature), 93 patients died of all causes, an increment of nearly $30 \%$ when compared with the expected mortality of 70 persons based in a French population of reference. Cancer-related mortality was not increased. Even though malignant neoplasm of bone and joint cartilage had an expected mortality of 0.6 , three patients who had received rhGH died. The expected mortality due to cardiomyopathy and cardiomegaly was of 0.28 , and two patients died. The expected mortality due to non-traumatic intracranial hemorrhages was of 0.6 , and four patients died $(23,24)$. The use of rhGH doses above $50 \mathrm{mcg} / \mathrm{kg} /$ day was associated with the highest mortality rate.

The investigators concluded that these preliminary data should be analyzed with caution due to the low event rate, limited power, and potentially undetected confounders. Another important aspect is that SAGhE preliminary data from Sweden, Belgium and the Netherlands, presented at the $50^{\text {th }}$ European Society of Pediatric Endocrinology Annual Meeting, in September 2011 , showed that from a total of 2,858 low risk patients, there were no deaths due to cancer, bone or cerebrovascular disease.

Sharing SAGhE main investigators' perspective, a Drug Safety Announcement by the FDA and the EMA stated that no change in the prescription of $\mathrm{rhGH}$ should be made before SAGhE study is concluded and new long-term surveillance studies are conducted $(25,26)$. 


\section{Chronic kidney disease}

Children with chronic kidney disease (CKD) fail to grow within the parental percentiles for multiple reasons, related and unrelated to the GH-IGF-1 axis $(27,28)$. The use of hGH in CKD growth disorder was approved by the FDA in 1993. Since then, it has been used in patients with predialytic CKD, in dialysis and after renal transplantation.

Before initiating rhGH therapy to CKD patients, it is imperative to improve nutritional status and to control metabolic acidosis, phosphorus and parathyroid hormone, so as to maximize GH actions on linear growth and to avoid the worsening of secondary hyperparathyroidism and the consequent development of bone deformities. Thus, phosphorus level should not be 1.5 times greater than the upper limit of normality (29).

Children with CKD-associated short stature in use of rhGH are more likely to develop BIH than those with other primary diseases (30), but not more likely than CKD patients without rhGH (31). Fine and cols. found no significant differences in the incidence of avascular necrosis, SCFE or any other serious adverse events, either (31).

As for the specific issues of CKD patients, the relationship between rhGH therapy and renal function has been thoroughly evaluated. Several studies show no effect on progression of kidney disease, deterioration of renal function or development of acute graft rejection (32-34).

\section{Turner syndrome and SHOX gene haploinsufficiency}

Turner syndrome (TS) is characterized by short stature, typical somatic features and delayed or absent spontaneous pubertal onset, with ovarian dysgenesis and consequent hypergonadotrophic hypogonadism. TS is caused by the complete or partial absence of the second X chromosome. Short stature homeobox (SHOX) gene is located in the pseudoautosomal region of both chromosomes X and Y. SHOX haploinsufficiency is believed to be the cause of short stature in TS, as well as in Leri-Weil dyschondrosteosis (OMIM \#127300), and Langer mesomelic dysplasia (OMIM \#249700).

\section{Orthopedic outcomes}

Children with TS should undergo orthopedic evaluation before initiating rhGH therapy. Scoliosis is one of the major concerns. From 49 TS girls followed by
Ricotti and cols., 29 exhibited scoliosis at baseline, and other 9 developed minor new scoliosis during the 4-year follow-up (35). It appears that rhGH may be related to worsening of preexisting scoliosis. TS is also at increased risk of SCFE, and close monitoring should be performed for early detection of epiphysiolysis.

\section{Nevi growth}

Melanocytic nevi may be present as a feature of TS, and nevi count is greater in these patients than in both GHD children and control subjects before starting rhGH. Despite the fact that rhGH is able to activate melanocyte proliferation, studies showed no relationship between the number of nevi and the duration of rhGH treatment in any group $(36,37)$. The incidence of skin cancer was not increased in TS children, either (38). These data demonstrates the benignity of melanocytic nevi in TS, and the absence of malignant transformation during rhGH therapy (38).

\section{Overall mortality}

Mortality in young TS girls is mostly due to congenital cardiac and aortic malformations, conditions that are unrelated to the use of rhGH. Neoplasms described in TS by Bolar and cols. are of different types and do not follow any specific pattern (39). The incidence of malignancies during $\mathrm{rhGH}$ treatment in this population did not reach statistical significance (39).

\section{Children born small-for-gestational age}

Ninety percent of children born small-for-gestational age (SGA) exhibit catch-up growth and reach familial height by the age of two (40). Some few children might undergo spontaneous catch-up growth between 2 and 4 years of age. The use of rhGH in SGA has been approved for children over 2 years-old by the FDA $(41,42)$, and it was also approved by the Latin American consensus (43). Differently, the European Medicines Agency (EMA) determined that 4-year old was the age to start rhGH therapy for SGA without catch-up growth (44).

SGA condition implicates an intrinsic increased risk of cardiovascular disease and insulin resistance in adulthood. However, at the moment, there are no published data reporting increased risk of any specific side effect in this population. Since the dose of rhGH used in this condition is higher than in GHD, long-term safety data is needed. 


\section{Prader-Willi syndrome}

Prader-Willi syndrome (PWS) is a genetic condition derived from the lack of expression of the paternally imprinted chromosome $15 \mathrm{qll}-\mathrm{ql}$, and is characterized by hypotonia, short stature, hyperphagia, hypogonadism, scoliosis, psychomotor delay, and behavioral abnormalities (OMIM \#176270).

Mortality rates in PWS are high when it is compared both with the general population and to people with intellectual disabilities from other causes (45). In infants and children, mortality is mainly due to sudden death and respiratory illness, and as they grow older, obesity and its complications, such as type 2 diabetes mellitus, hypertension, sleep apnea and cardiovascular disease, account for most of the deaths.

Since early 2000s, several cases of sudden death with a possible link to rhGH treatment have been reported (46). Further analysis did not show convincing data relating rhGH and mortality in this population. Since respiratory impairment is always a concern in PWS, it is advisable that, before initiating rhGH therapy, patients undergo a polysomnographic study. Nevertheless, there is no evidence linking the use of $\mathrm{rhGH}$ and respiratory morbidity in PWS (47).

Treatment with rhGH increases lean mass, decreases fat mass and improves the metabolic pattern of body fat distribution. In a long-term rhGH treatment study, there were no adverse effects in glucose homeostasis, blood pressure and lipid profile, and so it has been shown an effective and safe therapy for PWS patients (48).

Scoliosis is a common feature in PWS. Nakamura and cols. stated the prevalence at $38.6 \%$ (39 in a group of 101 patients) (49). Therapy with rhGH was found to induce neither the appearance nor the progression of scoliosis, affecting treated and untreated patients at equal rates $(48.8 \%$ vs. $41.9 \%, \mathrm{p}=0.56)(50)$. The incidence of SCFE is low in PWS both children with and without rhGH therapy $(11,51)$, even though obesity is closely related to the development of epiphysiolysis $(52,53)$.

\section{Idiopathic short stature (ISS)}

Idiopathic short stature (ISS) is a diagnosis of exclusion of children with height below -2SDS, and no clinical and laboratorial signs of underlying disease. Because there are many subgroups within this diagnosis, such as familial short stature and constitutional delay of growth and puberty, studies show quite heterogeneous response to hGH therapy (54).
A report by the NCGS cohort of 8,018 patients, with a total exposure to rhGH of 24,817 patient-years, found no serious side effects specific to patients with ISS (55). Even so, due to the heterogeneity of this condition and the occasional use of higher doses, long-term follow-up is necessary.

\section{Noonan syndrome}

The latest indication of hGH therapy approved so far by FDA was Noonan syndrome, clinically presented with short stature, typical facial features, and congenital heart defects. In most patients, NS is characterized by mutations on PTPN11 gene (OMIM \#163950). Although these mutations are closely related to the development of hematologic malignancies $(56,57)$, rhGH does not seem to add to its risk. Cardiac malformations are a common feature in the clinical findings of Noonan syndrome. Yet, there are no reports of adverse cardiovascular events of rhGH therapy in this population (58). The incidence of side effects is no different from the expected one among GHD patients.

In conclusion, treatment with rhGH has been approved for GHD and a number of other non-GH deficient patients with growth impairment. In each one, it has been shown that rhGH therapy is efficient in increasing growth velocity and final height. Mild side effects are not unusual, although they are frequently transient and tolerable. In contrast, serious adverse events that require discontinuation of the medication are rare, but need to be continuously monitored throughout the treatment. Further epidemiological studies are required to establish the long-term safety of rhGH therapy in adults who were on treatment during childhood.

Disclosure: Paulo Ferrez Collett-Solberg has received support from Merck-Serono, Novo Nordisk, and Pfizer to attend national and international scientific meetings. Flavio Moutinho Souza has no potential conflict of interest relevant to this article.

\section{REFERENCES}

1. Fradkin, JE. Creutzfeldt-Jakob disease in pituitary growth hormone recipients. Endocrinologist. 1993;3:108-14.

2. Richmond $E$, Rogol AD. Current indications for growth hormone therapy in children and adolescents. Endocr Dev. 2010;18:92-108.

3. Ogilvy-Stuart AL. Growth hormone deficiency (GHD) from birth to 2 years of age: diagnostic specifics of GHD during the early phase of life. Horm Res. 2003;60(suppl 1):2-9.

4. Ali O, Banerjee S, Kelly DF, Lee PD. Management of type 2 diabetes mellitus associated with pituitary gigantism. Pituitary. 2007;10(4):359-64.

5. Vicens-Calvet E, Seijo G, Potau N, de los Llanos Moreno M, Carrascosa $A$. Efectividad de la hormona de crecimiento recombi- 
nante en el déficit de talla debido a retraso de crecimiento intrauterino. Med Clin (Barc). 1999;112(16):601-5.

6. Hansen BR, Haugaard SB, Jensen FK, Jensen JE, Andresen L, Iversen $\mathrm{J}$, et al. Long-term high-physiological-dose growth hormone reduces intra-abdominal fat in HIV-infected patients with a neutral effect on glucose metabolism. HIV Med. 2010;11(4):266-75.

7. Cutfield WS, Wilton $P$, Bennmarker $H$, Albertsson-Wikland $K$, Chatelain $\mathrm{P}$, Ranke MB, et al. Incidence of diabetes mellitus and impaired glucose tolerance in children and adolescents receiving growth-hormone treatment. Lancet. 2000;355(9204):610.

8. Acharya SV, Gopal RA, BandgarTR, Menon PS, Shah NS. Prepubertal gynecomastia a rare complication of growth hormone therapy. Indian J Pediatr. 2010;77(4):443-4.

9. Malozowski S, Stadel BV. Prepubertal gynecomastia during growth hormone therapy. J Pediatr. 1995;126(4):659-61.

10. Loder RT. Slipped capital femoral epiphysis. Am Fam Physician. 1998;57(9:)2135-42.

11. Darendeliler F, Karagiannis G, Wilton P. Headache, idiopathic intracranial hypertension and slipped capital femoral epiphysis during growth hormone treatment: a safety update from the KIGS database. Horm Res. 2007;68(Suppl. 5):41-7.

12. Peck D. Slipped capital femoral epiphysis: diagnosis and management. Am Fam Physician. 2010;82(3):258-62.

13. de Andrade AC, Longui CA, Damasceno FL, Santili C. Southwick's angle determination during growth hormone treatment and its usefulness to evaluate risk of epiphysiolysis. J Pediatr Orthop B. 2009;18(1):11-5.

14. Collett-Solberg PF, Liu GT, Satin-Smith M, Katz LL, Moshang T Jr. Pseudopapilledema and congenital disc anomalies in growth hormone deficiency. J Ped Endocrinol Metabol. 1998;11,261-5.

15. Watanabe S, Mizuno S, Oshima LH, TsunematsuY, Fujimoto J, Komiyama A. Leukemia and other malignancies among GH users. J Pediatr Endocrinol. 1993;6(1):99-108.

16. Seif AE. Pediatric leukemia predisposition syndromes: clues to understanding leukemogenesis. Cancer Genet. 2011;204(5):227-44.

17. Allen DB. Safety of human growth hormone therapy: Current topics. J Pediatr. 1996;128(5 pt 2):S8-13.

18. Sklar CA, Mertens AC, Mitby P, Occhiogrosso G, Qin J, Heller G, et al. Risk of disease recurrence and second neoplasms in survivors of childhood cancer treated with growth hormone: a report from the Childhood Cancer Survivor Study. J Clin Endocrinol Metab. 2002;87(7):3136-41.

19. Ergun-Longmire B, Mertens AC, Mitby P, Qin J, Heller G, Shi W, et al. Growth hormone treatment and risk of second neoplasms in the childhood cancer survivor study. J Clin Endocrinol Metab. 2006;91:3494-8.

20. Nishio S, Morioka T, Inamura T, Takeshita I, Fukui M, Sasaki M, et al. Radiation-induced brain tumours: potential late complications of radiation therapy for brain tumours. Acta Neurochir (Wien). 1998;140:763-70.

21. Mackenzie S, Craven T, Gattamaneni HR, Swindell R, Shalet SM, Brabant G. Long-term safety of growth hormone replacement after CNS irradiation. J Clin Endocrinol Metab. 2011;96:2756-61.

22. Burgers AM, Biermasz NR, Schoones JW, Pereira AM, Renehan $A G$, Zwahlen $M$, et al. Meta-analysis and dose-response metaregression: circulating insulin-like growth factor I (IGF-I) and mortality. J Clin Endocrinol Metab. 2011;96(9):2912-20.

23. Carel J-C, Ecosse E, Landier F, Meguellati-Hakkas D, Kaguelidou F, Rey G, et al. Long-term mortality after recombinant growth hormone treatment for isolated childhood short stature: report of the French SAGhE study. Endocr Rev. 2011;32(03_ MeetingAbstracts):LB-5.

24. Agence Française de Sécurité Sanitaire dês Produits de Santé. Hormone de Croissance synthétique (somatropine recombinante): Premiers résultats de l'étude épidémiologique sur la tolérance à long terme. 2010. Available at: http://www.afssaps. $\mathrm{fr} /$ Infos-de-securite/Communiques-Points-presse/Hormone-de-Croissance-synthetique-somatropine-recombinante-Premiers-resultats-de-l-etude-epidemiologique-sur-la-tolerance-a-long-terme-Communique. Accessed on: Sept 4, 2011.

25. Carel J-C, Coste J. Information concerning the communication of preliminary results of the French SAGhE study. 2010. Available at: http://saghe.aphp.fr/site/IMG/pdf/Information_concerning_the communication_of_preliminary_results_of_the_French_SAGhE_ study.pdf. Accessed on: Sept 4, 2011.

26. FDA drug safety communication: ongoing safety review of recombinant human growth hormone (somatropin) and possible increased risk of death. 2011. Available at: http://www.fda.gov/ Drugs/DrugSafety/ucm237773.htm. Accessed on: Sept 4, 2011.

27. Oliveira JO, Siviero-Miachon AA, Spinola-Castro AM, Belangero VMS, Guerra-Junior G. Baixa estatura na doença renal crônica: fisiopatologia e tratamento com hormônio de crescimento. Arq Bras Endocrinol Metab. 2008;52(5):783-91.

28. Mahan JD, Warady BA. Consensus committee. Assessment and treatment of short stature in pediatric patients with chronic kidney disease: a consensus statement. Pediatr Nephrol. 2006;21:917-30.

29. Kaufman DB. Growth hormone and renal osteodystrophy: a case report. Pediatr Nephrol. 2008;12:157-9.

30. Blethen SL, Allen DB, Graves D, August G, Moshang T, Rosenfeld R. Safety of recombinant deoxyribonucleic acid-derived growth hormone: The National Cooperative Growth Study experience. J Clin Endocrinol Metab. 1996;81(5):1704-10.

31. Fine RN, Ho M, Tejani A, Blethen S. Adverse events with rhGH treatment of patients with chronic renal insufficiency and end-stage renal disease. J Pediatr. 2003;142:539-45.

32. Wiihl E, Haffner O, Gretz N, Offner G, van't Hoff WG, Broyer M, et al.; The European Study Group on Growth Hormone Treatment in Short Children with Nephropathic Cystinosis. Treatment with recombinant human growth hormone in short children with nephropatic cystinosis: no evidence for increased deterioration rate of renal function. Pediatr Res. 1998;43:484-8.

33. Hokken-Koelega AC, Stijnen T, de Ridder MA, de Muinck Keizer-Schrama SM, Wolff ED, de Jong MC, et al. Growth hormone treatment in growth-retarded adolescents after renal transplant. Lancet. 1994;343:1313-7.

34. Fine RN, Stablein D, Cohen AH, Tejani A, Kohaut E. Recombinant human growth hormone post-renal transplantation in children: a randomized controlled study of the NAPRTCS. Kidney Int. 2002;62:688-96.

35. Ricotti S, Petrucci L, Carenzio G, Klersy C, Calcaterra V, Larizza D, et al. Prevalence and incidence of scoliosis in Turner syndrome: a study in 49 girls followed-up for 4 years. Eur J Phys Rehabil Med. 2011;47(3):447-53.

36. Bourguignon JP, Piérard GE, Ernould C, Heinrichs C, Craen M, Rochiccioli $P$, et al. Effects of human growth hormone therapy on melanocytic naevi. Lancet. 1993;341(8859):1505-6.

37. Piérard GE, Piérard-Franchimont $C$, Nikkels A, Nikkels-Tassoudji $\mathrm{N}$, Arrese JE, Bourguignon JP. Naevocyte triggering by recombinant human growth hormone. J Pathol. 1996;180(1):74-9.

38. Wyatt $D$. Melanocytic nevi in children treated with growth hormone. Pediatrics. 1999;104(4 Pt 2):1045-50.

39. Bolar K, Hoffman AR, Maneatis T, Lippe B. Long-term safety of recombinant human growth hormone in turner syndrome. J Clin Endocrinol Metab. 2008;93:344-51.

40. Albertsson-Wikland K, Karlberg J. Postnatal growth of children born small for gestational age. Acta Paediatr Suppl. 1997;423:193-5.

41. Lee PA, Chernausek SD, Hokken-Koelega AC, Czernichow P. International small for gestational age advisory board consensus development conference statement: management of short children born small for gestational age, April 24-October 1, 2001. Pediatrics. 2003;111:1253-61. 
42. Gharib H, Cook DM, Saenger PH, Bengtsson BA, Feld S, Nippoldt TB, et al.; American Association of Clinical Endocrinologists Growth Hormone Task Force 2003. American Association of Clinical Endocrinologists medical guidelines for clinical practice for growth hormone use in adults and children-2003 update. Endocr Pract. 2003;9:64-73.

43. European Agency for the Evaluation of Medicinal Products: Committee for Proprietary Medicinal Products (CPMP) 2003 Norditropin. Available at: http://www.ema.europa.eu/pdfs/human/referral/ norditropin/347803en.pdf. Accessed on: Sept 4, 2011.

44. Boguszewski MCS, Mericq V, Bergada I, Damiani D, Belgorosky A, Gunczler P, et al. Latin American Consensus: Children Born Small for Gestational Age. BMC Pediatr. 2011;11:66.

45. Einfeld SL, Kavanagh SJ, Smith A, Evans EJ, Tonge BJ, Taffe J. Mortality in Prader-Willi Syndrome. Am J Ment Retard. 2006;111(3):193-8.

46. Tauber M, Diene G, Molinas C, Hébert M. Review of 64 cases of death in children with Prader-Willi syndrome (PWS). Am J Med Genet A. 2008;146(7):881-7.

47. Lee PDK. Growth hormone and mortality in Prader Willi syndrome. GGH Journal. 2006;22(2):17-23.

48. van Wijngaarden RFA de $L$, Siemensma EPC, Festen DAM, Otten BJ, van Mil EGAH, Rotteveel J, et al. Efficacy and safety of long-term continuous growth hormone treatment in children with Prader-Willi syndrome. J Clin Endocrinol Metab. 2009;94:4205-15.

49. Nakamura Y, Nagai T, lida T, Ozeki S, Nohara Y. Epidemiological aspects of scoliosis in a cohort of Japanese patients with Prader-Willi syndrome. Spine J. 2009;9(10):809-16.
50. Nagai T, Obata K, Ogata T, Murakami N, Katada Y, Yoshino A, et al. Growth hormone therapy and scoliosis in patients with Prader-Willi syndrome. Am J Med Genet A. 2006;140(15):1623-7.

51. West LA, Ballock RT. High incidence of hip dysplasia but not slipped capital femoral epiphysis in patients with Prader-Willi syndrome. J Pediatr Orthop. 2004;24(5):565-7.

52. Poussa M, Schlenzka D, Yrjönen T. Body mass index and slipped capital femoral epiphysis. J Pediatr Orthop B. 2003;12(6):369-71.

53. Murray AW, Wilson NI. Changing incidence of slipped capital femoral epiphysis: a relationship with obesity? J Bone Joint Surg Br. 2008;90(1):92-4.

54. Cohen $P$, Rogol AD, Deal CL, Saenger P, Reiter EO, Ross JL, et al.; on behalf of the 2007 ISS Consensus Workshop participants. Consensus statement on the diagnosis and treatment of children with idiopathic short stature: a summary of the Growth Hormone Research Society, the Lawson Wilkins Pediatric Endocrine Society, and the European Society for Paediatric Endocrinology Workshop. J Clin Endocrinol Metab. 2008;93:4210-17.

55. Kemp SF, Kuntze J, Attie KM, ManeatisT, Butler S, Frane J, et al. Efficacy and safety results of long-term growth hormone treatment of idiopathic short stature. J Clin Endocrinol Metab. 2005;90:5247-53.

56. Grossmann KS, Rosário M, Birchmeier C, Birchmeier W. The tyrosine phosphatase Shp2 in development and cancer. Adv Cancer Res. 2010;106:53-89.

57. Liu X, Qu CK. Protein Tyrosine Phosphatase SHP-2 (PTPN11) in Hematopoiesis and Leukemogenesis. J Signal Transduct 2011;2011:195239. Epub 2011 Jun 7.

58. Noordam C. Growth hormone and the heart in Noonan syndrome. Horm Res. 2009;72 Suppl 2:49-51. 